\title{
Esophageal Perforation Surgical Management
}

\author{
Burkan Nasr* \\ Consultant General and Laparoscopic surgery, Al Thawra Modern General/ Teaching Hospital, Sana 'a and Suadi Hospital at \\ Hajjah, Yemen
}

*Corresponding author: Burkan Nasr Rashed Shaif, MD, FEBS, MRCS, FRCS, FACS, Consultant General and Laparoscopic surgery, Al Thawra Modern General/ Teaching Hospital,Sana`a and Suadi Hospital at Hajjah, Yemen E-mail: Burkan.naser@yahoo.com

\section{ARTICLE INFO}

Received: 幽 November 16, 2021

Published: 慧 November 22, 2021

Citation: Burkan Nasr. Esophageal Perforation Surgical Management. Biomed J Sci \& Tech Res 40(1)-2021. BJSTR. MS.ID.006405.

\section{ABSTRACT}

The esophageal perforation remains a potentially devastating condition. Rapid diagnosis and therapy provide the best chance for survival; however, delay in diagnosis is common, resulting in substantial morbidity and mortality. This article discusses the diagnosis and Surgical Management for this potentially lethal Gastrointestinal condition.

Keywords: Esophageal perforation, Surgery in esophagus, Boerhaave's syndrome, Esophageal cancer, Achalasia

\section{Introduction}

Esophageal perforation is commonly a life-threatening emergency. The majority of perforations $(60 \%)$ are iatrogenic following endoscopy, esophageal dilatations. Trauma accounts for approximately $20 \%$ of esophageal perforations and spontaneous rupture for another $15 \%$. Boerhaave's syndrome, perforation of the esophagus, is caused by forceful or increased intra-abdominal pressure.

Endoscopic injury typically occurs in two main site (proximal at esophageal entroitus and distally at site of pathology) the latter is the most common occurrence ( $80 \%$ cases).

The reported mortality from treated esophageal perforation is $10 \%$ to $25 \%$, when therapy is initiated within 24 hours of perforation, but it could rise up to $40 \%$ to $60 \%$ when the treatment is delayed beyond 48 hours [1].

\section{Discussion}

Symptoms vary according to the location of perforation, size of the perforation, and time duration since injury. Cervical perforations may present with neck pain, dysphagia, and odynophagia. Palpation of the neck may reveal emphysematous crepitus. Thoracic perforations may present with substernal or epigastric pain as well as dysphagia. Abdominal perforations usually present with epigastric pain radiating to the back or left shoulder with signs of peritoneal irritation. Early diagnosis are important step in patients with Esophageal perforation, The diagnostic study of choice in any patient suspected of having an esophageal perforation is a contrast radiograph of the esophagus. A water soluble contrast esophagogram followed by barium, if necessary, is diagnostic in $90 \%$ of patients. CT scan of the chest and upper abdomen with oral contrast is also used with more frequency are more sensitive to localize site of perforation , area of necrosis or fluid collection in mediastinal or pleural cavity. The plain chest radiograph less sensitive may appear normal early after esophageal perforation but however present pneumomediastinum, subcutaneous emphysema, pleural effusion, and hydropneumothorax, these findings in chest $\mathrm{x}$. Ray highly suggestive of esophageal perforation [2,3].

Treatment should also be stepwise with consideration given to: patients clinical status and stability, Time since perforation, Location/size of the perforation, the extent of tissue necrosis and degree of contamination, the presence of underlying esophageal disease or disorder (Barrett's,malignancy,achalasia ..ets).

If esophageal perforation is suspected, immediate treatment should begin with cessation of all oral intake, intravenous fluid 
resuscitation, gastric decompression, and broad-spectrum antibiotic therapy to cover both aerobic and anaerobic organisms. In the stable patient no sepsis with minimum or mild symptoms, with walled-off small perforation and well contained leak on esophagogram, nonoperative management can be successful. Patients meeting these criteria can be managed with cessation of oral intake, total parenteral nutrition, and antibiotics. If there is evidence of pleural contamination, drainage of pleural contents can be performed via placement of a chest tube or video-assisted thoracoscopic decortication.

A repeat esophagogram is performed in 7-14 days. Oral intake may be resumed following resolution or stabilization of the leak. This patients low threshold to take to operation but need frequent reassessments if there are Signs of clinical deterioration with conservative management, should prompt surgical intervention. In the absence of underlying esophageal pathology such as malignancy, primary repair with drainage of the contaminated area should be initially considered. This option is best suited for patients with early presentation within 24 hours demonstrating, minimum hemodynamic instability and mild to moderate contamination. Primary repair is performed by exposing the entire length of mucosal injury, debriding any nonviable tissue, and closing the defect by interrupted suture in two layers including the submucosal layer and muscular wall. The suture line can then be reinforced with a flap of parietal pleura, intercostal muscle, or gastric fundus , but this option also can be modified according to the site of perforation, for perforations in upper two thirds of esophagus, right thoracotomy, debridement of all nonviable tissue, myotomy to define extent of mucosal injury, closure in two layers over nasogastric tube (NGT), cover with tissue flap (pleural/pericardium/intercostal muscle), and place chest tube.

The patient is then kept nill per oral (NPO), on total parenteral nutrition (TPN) or enteral feeds through naso_jejunostomy or jejunostomy tube feeding and continue antibiotics. for perforation in lower third of esophagus, left thoracotomy and same procedure as above with ability to cover repair with Thal patch, diaphragm muscle, fundoplication . for perforation in abdominal esophagus, upper midline with low threshold to making left thoracotomy and cover repair with fundoplication . for cervical perforation, incision in left neck along the sternocleidomastoid (SCM) muscle. In the setting of hemodynamic instability or frank sepsis, the patient may not tolerate a lengthy procedure. In this situation, Proximal drainage through a cervical esophagostomy (so-called spit fistula) and debridement of of contamination area in mediastinum, site of esophageal perforation and leave esophagus open with establish effective drainage with chest tubes, continue antibiotics and early enteral nutrition through jejunostomy tube feeding. When perforation is associated with underlying esophageal disease, any pathology causing distal obstruction mustbe addressed to prevent breakdown of a primary repair.

In the setting of achalasia, a distal esophagomyotomy on the side opposite of the perforation should be performed in addition to primary repair and partial gastric fundoplication buttress of the perforation site. Perforations accompanied by esophageal malignancy or severe contaminations in stable patients are best treated with esophageal resection or Proximal drainage through a cervical esophagostomy and feeding tube are appropriate in anticipation of a delayed reconstruction, in case of inoperable self expanding stent can be inserted to control the leak [1][3][4] [5]. The introduction of covered, removable, self-expanding stent technology that is easily deployed, restricts mucosal ingrowth, and is adjustable if migration does occur has led to widespread use by thoracic surgeons for both iatrogenic and benign esophageal perforations. The introduction of expandable bare metal stents and Increased experience with stents has led to expanded use in patients presenting with iatrogenic perforations, particularly after delayed presentation and in those with significant associated mediastinal/pleural contamination. Also use stents expanding to include patients following early presentation who traditionally have reasonable outcomes compared with open surgical repair [4] [5][6].

\section{Conclusion}

Successful management depending on early recognition and initiation of treatment. The morbidity and mortality rate is directly related to the delay in diagnosis and initiation of optimum treatment. Without treatment, frank sepsis, respiratory failure and death may develop.

\section{References}

1. Kaman L, Iqbal J, Kundil B, Kochhar R (2010) Management of Esophageal Perforation in Adults. Gastroenterology Res 3(6): 235-244.

2. Lampridis S, Mitsos S, Hayward M, Lawrence D, Panagiotopoulos N (2020) The insidious presentation and challenging management of esophageal perforation following diagnostic and therapeutic interventions. J Thorac Dis 12(5): 2724-2734.

3. White RK, Morris DM (1992) Diagnosis and management of esophageal perforations. Am Surg 58(2): 112-119.

4. Zumbro GL, Anstadt MP, Mawulawde K, Bhimji S, Paliotta MA, et al. (2002) Surgical management of esophageal perforation: role of esophageal conservation in delayed perforation. The American Surgeon 68(1): 3640 .

5. Blasberg JD, Wright CD (2013) Management of esophageal perforation. In: Sugarbaker DJ, Bueno R, Colson YL, et al., (Eds.)., Adult Chest Surgery ( $2^{\text {nd }}$ Edn.)., New York, NY: McGraw-Hill, p. 48.

6. Brinster CJ, Singhal S, Lee L, Marshall MB, Kaiser LR, et al. (2004) Evolving options in the management of esophageal perforation. Ann Thorac Surg 77(4): 1475-1483. 
ISSN: 2574-1241

DOI: 10.26717/BJSTR.2021.40.006405

Burkan Nasr. Biomed J Sci \& Tech Res

(c) (P) This work is licensed under Creative

Submission Link: https://biomedres.us/submit-manuscript.php

$\begin{array}{ll}\text { BIOMEDICAL } & \text { Assets of Publishing with us } \\ \text { RESEARCHES } & \text { - Global archiving of articles } \\ \text { - Immediate, unrestricted online access } & \text { - Rigorous Peer Review Process } \\ & \text { - Authors Retain Copyrights } \\ \end{array}$

